\title{
Queering Virtual Reality: A Prolegomenon
}

\author{
Dylan Paré; Pratim Senguptał Scout Windsor, John Craig, \\ and Matthew Thompson"
}

\begin{abstract}
In this chapter, we investigate how innovations in STEM, such as Virtual Reality (VR) and 3D Sculpting, can support the development of critical literacies about gender and sexuality. Our work arises from the concern that the assumed "naturalness" of male/female binary categories in biology is often at the center of the queer, trans, and intersex panics in public education. Echoing sociologists and critical scholars of gender and sexuality, we posit that transgender and queer identities should be positioned as realms of playful, active inquiry. Further, we investigate how new forms of computational representational infrastructures can be leveraged to support productive and playful experiences of inquiry about gender and sexuality. We present a retrospective analysis of a design group meeting of a small group of friends in their early thirties with gender nonconforming and queer identities and life histories. The group interacted in VR-based environments, where they engaged in two different forms of constructionist learning experiences: creating 3D sculptures of personally meaningful objects, and re-creating their VR avatars in VR social media. Our analysis illustrates how such experiences can be productively analyzed using social constructivist perspectives that situate knowing as boundary play and figured worlds, and the roles that play and friendship have in supporting deep and critical engagement with complex narratives and marginalized experiences of gender and sexuality.
\end{abstract}

\section{Introduction}

In this chapter, we investigate how innovations in STEM, such as Virtual Reality (VR) and 3D Sculpting, can support the development of critical literacies about gender and sexuality. Our work is motivated by the concern that the assumed "naturalness" of male/female binary categories in biology (Bazzul \& Sykes, 2011; Westbrook \& Schilt, 2014) is often at the

\footnotetext{
*Author for correspondence. Email: dylan.pare@ucalgary.ca

$\dagger$ University of Calgary

$\ddagger$ University of Calgary

$\S$ WakeBold

IUniversity of Calgary

$\|$ Telus SPARK Science Center
} 
In: Sengupta et al. (Eds.) Critical, Transidisciplinary and Embodied Approaches in STEM Education (pp 307 - 328). Springer. Link: https://link.springer.com/chapter/10.1007/978-3-030-29489-2_17

center of the queer, trans, and intersex panics in public education and sexsegregated spaces. This also undergirds oppressive legislation and cultural policing of trans people's access to sex-segregated bathrooms (Cavanagh, 2010), medical panics that create perceived "emergencies" around assigning a binary sex to intersex people (Davis, 2015; Davis \& Murphy, 2013), and the panic in sports over whether and in which gender category intersex or trans athletes can compete (Karkazis, Jordan-Young, Davis, \& Camporesi, 2012; Travers, 2017). To challenge this assumed naturalness of male/female binary categories especially in pedagogical contexts, echoing Thorne's (1993) call for re-considering gender as social action and not merely as a category, Grace (2015) argued that we need to reconsider transgender and queer identities as "a realm of active inquiry, play and creative expression" (p. 49). Building on this work, our chapter investigates how new forms of computational representational infrastructurese.g., 3D Sculpting in VR - can be leveraged to support productive and playful experiences of inquiry about gender and sexuality.

Empirical research has also shown that embodied interactions and projections in virtual worlds - the fundamental form of experience in VR environments - can help people take on perspectives that would be otherwise difficult for them to adopt, in complex topics ranging from physics and chemistry to animal rights, racism, and ageism (Abrahamson \& Lindgren, 2014; Ahn, Le, \& Bailenson, 2013; Groom, Bailenson, \& Nass, 2009; Hostetler, Sengupta, \& Hollett, 2018; Lindgren \& Johnson-Glenberg, 2013; Oh, Bailenson, Weisz, \& Zaki, 2016; Peck, Seinfeld, Aglioti, \& Slater, 2013; Vea, 2019). Our chapter furthers this line of work by illustrating the roles of play, friendship, and embodiment in the context of creating and exploring complex representations of gender and sexuality in immersive VR. And, while sociologists and gender scholars have shown that informal gender play and conversations with friends shape and/or reify our understanding of gender and sexual identities (Risman \& Banerjee, 2013; Thorne, 1993), there is little understanding of how such playful experiences with friends can be leveraged to support the development of a more socially just epistemology of queerness and transgender identities.

We present a retrospective analysis of a design group meeting involving all five authors, with a focus on the four authors who are friends in their early thirties with gender nonconforming and queer identities and life histories. These participants engaged in two different forms of constructionist learning experiences in VR-based environments: creating 3D sculptures of personally meaningful objects, and re-creating their VR avatars in VR social media. Our analysis illustrates how VR-based learning environments can be designed to support productive and playful learning experiences about gender and sexuality, and furthermore, how such experiences can be productively analyzed using social constructivist perspectives that situate knowing as boundary play and figured worlds (Holland, Lachicotte Jr., Skinner, \& Cain, 1998; Sengupta \& Shanahan, 2017). 
In: Sengupta et al. (Eds.) Critical, Transidisciplinary and Embodied

Approaches in STEM Education (pp 307 - 328). Springer. Link:

https://link.springer.com/chapter/10.1007/978-3-030-29489-2_17

\section{Theoretical Background}

\subsection{Play, Friendships, Figured Worlds, and Piv- ots}

Learning scientists have shown that playful learning environments can greatly facilitate learning of complex topics across a range of disciplines (Berland \& Lee, 2011; Kim \& Ho, 2018; Sengupta \& Shanahan, 2017). Following Vygotsky (1980), Holland et al. (1998) argue, it is through play that imagination becomes embodied. In this view, play can be seen as the experience of imagination, and Vygotsky also argues that it is deeply connected with desire, albeit in the context of children's development. Play thus creates contexts for us to experience virtuality, which as Leander and Boldt (2018) argue, is about "what could happen that is unplanned, undesigned" (p. 35). This is because in play, the meanings and imaginations of, rather than the mere physicality of the objects shape the experience of the participants. The context of play thus brings into the picture learners' desires, which goes beyond both the notions of designing learning environments and the teachers' and designers' intentionalities (Leander \& Boldt, 2018; Massumi, 2002). Leander and Boldt (2018) argue that this leads to difference making, where learners' experiences unfold in a non-deterministic manner, often differently from the curriculum-not necessarily within the curricular activities.

This is also resonant with the scholarship on playful learning, which shows that when learners are playfully engaged in a virtual environment, they can (re)shape the learning activities even within a structured setting, such that the activities are both personally meaningful and relevant to the disciplinary context of learning (Azevedo, 2018; Farris \& Sengupta, 2016; Kim \& Ho, 2018). These activities range from problem-solving to invention, modification, and transgression of the underlying rules that govern the virtual environment (Kim \& Ho, 2018), and even bringing together, unexpectedly, different disciplines and realms of experience (Sengupta \& Shanahan, 2017). In such contexts, learners are positioned in agentive roles, i.e., in ways that enable them to engage in a deeper exploration and inquiry of canonical practices and ideas through manipulating and even transgressing them, as well as through affective engagement (Kim \& Ho, 2018).

One might then ask: What is the nature of imagination that can arise through such forms of play? The notion of figured worlds is useful in answering this question. Holland et al. (1998) argue that, "... [Play] allows for the emergence of new figured worlds, of refigured worlds that come eventually to reshape selves and lives in all seriousness" (p. 236). Figured worlds are "sociohistoric, contrived interpretations or imaginations that mediate behaviour and so, from the perspective of heuristic development, inform participants' outlooks. The ability to sense (see, hear, touch, taste, feel) the figured world becomes embodied over time, through continual participation" (Holland et al., 1998, pp. 52-53). In this view, figured worlds manifest themselves in the form of people's activities and practices. Pivots play an important role in the experiences of our participants in the context of their representational work of building identity 
In: Sengupta et al. (Eds.) Critical, Transidisciplinary and Embodied Approaches in STEM Education (pp 307 - 328). Springer. Link: https : //link.springer. com/chapter/10.1007/978-3-030-29489-2_17

artifacts. Building on Vygotsky (1980), Holland et al. (1998) argue that pivots are culturally defined artifacts that shift the frame of an activity and evoke or "'open up' figured worlds" (p. 61). The elements of a figured world - its artifacts, storylines, characters and their concerns, and the activities - help in positioning oneself meaningfully in relation to the figured world and can also serve as pivots. Pivots enable participants to swivel across multiple figured worlds. This swiveling back and forth between multiple figured worlds can also take the form of boundary play (Sengupta \& Shanahan, 2017), where the pivots act as boundary objects at the intersection of multiple social worlds. The primary feature of pivots is that the same objects are meaningful in multiple social worlds, even though those meanings may be different or even contradictory. Sengupta and Shanahan (2017) show that boundary play in computational worlds allows learners to meaningfully bring together multiple figured worlds in the context of interpreting and explaining complex phenomena. In the context of our work, we believe that the notions of figured worlds, boundary play, and pivots can be useful for understanding queer and trans experiences as they unfold in virtual reality environments.

Finally, we draw from a small but growing body of research on the relationship between friendship and learning. While some studies show that the dynamics within friendships may sometimes present challenges for learning (Esmonde, Brodie, Dookie, \& Takeuchi, 2009; Mitchell, Reilly, Bramwell, Solnosky, \& Lilly, 2004), Takeuchi (2016) found that group work with friends can also offer greater opportunities for access to a wider variety of complex, disciplinary work practices and positional identities, for example, by enabling students to take on roles of both experts and learners. Takeuchi's work further shows that learning with friends can be particularly helpful for marginalized learners, whose lived experiences outside the classroom often become the sources of social isolation and marginalization within the classroom. Furthermore, sociologists have also shown that informal interactions and conversations with friends play a formative role for the development of gender and sexual identities for children and youth. This is evident in several forms, such as informal gender play (Thorne, 1993), and informal discourse about gender, sex, and sexuality (Risman \& Banerjee, 2013).

\subsection{Emergent and Figured Worlds of Queerness, Body-Becoming, and Compulsory Heterosexuality}

We draw from queer theory, specifically Butler's (2006) concept of the heterosexual matrix, Ahmed's (2006) queer phenomenology, as well as from Lane's (2009) call for trans and queer studies to engage with a fundamentally more complex, new materialist biology and the concept of the bodybecoming. A proliferation of language to describe the assumed naturalness of the gender binary and how it is reinforced through heterosexuality arose out of lesbian and gay studies scholarship in the 1980s and 1990s, including Butler's (2006/1990) heterosexual matrix, Adrienne Rich's (1980) compulsory heterosexuality, Monique Wittig's (1980) heterosexual contract, and heteronormativity by Michael Warner in 1991 (Jeppesen, 2016). 
In: Sengupta et al. (Eds.) Critical, Transidisciplinary and Embodied Approaches in STEM Education (pp 307 - 328). Springer. Link: https://link.springer.com/chapter/10.1007/978-3-030-29489-2_17

The heterosexual matrix highlights the social system of constraints shaping understandings of gender and sexuality, where bodies are expected "to cohere and make sense" by expressing a stable, binary sex and gender through compulsory heterosexuality (Butler, 2006, p. 208). Beyond Butler's (2006) notion of the heterosexual matrix, Ahmed (2006) further argued that bodies take shape as an effect of how they are continuously oriented within the world through the experience of compulsory heterosexuality. Ahmed wrote that bodies become "contorted" (Ahmed, 2006, p. 67), through repeating specific gestures (and not others), or through being orientated in specific directions (and not others). The metaphor of contortion indicates that our bodies get "twisted" into shapes that enable some action "only insofar as they restrict the capacity for other kinds of action. Compulsory heterosexuality diminishes the very capacity of bodies to reach what is off the straight line" (Ahmed, 2006, p. 67).

Ahmed's work offers a way to see how gender and sexuality are produced in everyday moments of interaction with objects, others, and the spaces we inhabit. In this light, our everyday experiences, including language, can be seen as oriented towards heteronormativity, which is reinforced socially, institutionally, politically, and culturally. However, as both Butler (2006/1990) and Ahmed (2006) pointed out, what makes this more complicated is that gender and sexuality are typically experienced as originating from within oneself, and the interactions which reproduce the gendered subject are displaced and hidden from view. Ahmed (2006) explains what it takes to go "off the straight line," using the example of being/becoming a lesbian: "It takes time and work to inhabit a lesbian body; the act of tending toward other women has to be repeated, often in the face of hostility and discrimination, to gather such tendencies into a sustainable form" (p. 78).

However, it has also been argued that by focusing primarily on homosexuality as a means to disrupt heteronormativity, earlier scholarship in lesbian, gay, and queer studies failed to recognize how transgender experiences could be antiheteronormative (Stryker, 2013). Thus, transgender studies emerged alongside - sometimes within, and sometimes in opposition to - lesbian and gay studies and queer studies, and from this history, developed its own language to highlight transgender experiences (Currah \& Stryker, 2014). This language includes cisnormativity and cisheteronormativity, which indicate the co-occurrence and/or intertwinement of both cisnormativity and heteronormativity in our everyday experiences. In this context, it is important to note that Ahmed's approach to understanding queer experiences-i.e., non-dominant and marginalized experiences related to gender and sexuality - aligns with Lane's (2009) new materialist approach to queer and trans studies which argues that "feminist analysis needs to move from ideas of the body as constraining, fixed, and given toward ideas of the 'body becoming' as dynamic, transformative process" (p. 141). In this perspective, the body is both the place where gender is experienced, and a dynamic and public representation of one's gender and sexual identities. To actively take up the "body-becoming" approach to understanding gender and sexuality, we must recognize how gender and sexuality are dynamically shaped and experienced in the body within interactions. This is where Ahmed's work provides a productive analytic 
In: Sengupta et al. (Eds.) Critical, Transidisciplinary and Embodied Approaches in STEM Education (pp 307 - 328). Springer. Link: https://link.springer.com/chapter/10.1007/978-3-030-29489-2_17

framework for understanding gender and sexuality phenomenologically by attending to how we turn towards or away from certain objects, others, and places as well as how objects, others, and places in turn might offer opportunities for the extension of our bodies.

The analytic framework we use combines the theoretical work in queer and trans studies with the literature on figured worlds (Holland et al., 1998). We posit that compulsory heterosexuality can be interpreted as a figured world because it comes to be inscribed upon the body, and embodied as part of one's identity, through everyday participation in reproducing the figured world. As will become evident in our analysis in the following sections, boundary play in VR involves the creation and use of pivots in the form of $3 \mathrm{D}$ sculptures, reflections and conversations around which can help us engage in both personally meaningful and socially disruptive discourse about heteronormativity.

\section{$3 \quad$ Virtual Reality Environments Used in this Work}

We used two applications during the project, Oculus Medium and Facebook Spaces. Oculus Medium is a VR digital sculpting application which allows the user to sculpt an object floating in space in front of them within the virtual environment. The user places digital "clay" in the environment and then can shape the clay into whatever object they desire using a variety of digital tools. The application also has a feature called Studio Share which allows a user to invite a friend (their Oculus accounts must be linked as friends) to sculpt in the same virtual space. The users can see and hear each other in real time and both can see what each person is sculpting. They can sculpt directly in the space that the other is sculpting, but they cannot alter the other person's sculpture. This application was chosen for two reasons. First, one of our participants, Scout, is a professional digital, VR sculptor. We designed the sculpting activity so that Scout could support other participants in learning to navigate the new application.

The second application used during the research was Facebook Spaces. We originally had not included Facebook Spaces in the design of the research, but during a break one participant, Matthew, suggested we try out the application. It is an explicitly social application that relies upon you and your friends all being available at the same time and Matthew saw the research event as an opportunity to try out the application since he had three of his friends available. In Facebook Spaces, one user invites up to three other people to join the same virtual environment. Since we only had three VR systems available, we could only have three participants in the virtual environment at one time. We used the version of Facebook Spaces that was available in late 2017. The application has since been updated and some of the functions described below have changed.

Within the Facebook Spaces virtual environment, the users embody avatars that are positioned around a circular table. Users can speak and gesture with their hands and head to friends around the table without 
In: Sengupta et al. (Eds.) Critical, Transidisciplinary and Embodied

Approaches in STEM Education (pp 307 - 328). Springer. Link:

https://link.springer.com/chapter/10.1007/978-3-030-29489-2_17

requiring their physical presence. The application requires users to sign in with a Facebook social media account when launching the application. Once in the virtual environment, the user can play with virtual objects in the space such as dice, a drawing pen, a selfie stick, or virtual fishing game. The user can also connect with media they have shared on their Facebook account to display it in the virtual environment to their friends, or the user can access public media content available within the application, such as $360^{\circ}$ photos and videos. Users can also modify their avatars while looking into a virtual mirror at their avatar, using preset options that are organized into the following categories: eyes, nose, head shape, skin color, hair style and colors, ears, mouth, eyebrows, facial hair, T-shirt color, and glasses. Color options for eyes include two shades of blue, four shades of green/hazel, and three shades of brown. Skin color includes 14 shades that run from pale beige to dark-medium brown. Seventy-two hairstyles are included and nine natural hair colors, including grey, orange, red, two shades of blond, three shades of brown, and black. Sixteen mouth shapes and 14 shades of lip colors are included, including one natural skin color that changes shades depending on the user's selected skin color, as well as non-natural lip colors, including blue, purple, turquoise, green, black, and various shades of pink. The user also has the option of having the application analyze a Facebook profile photo that the user selects from a list of polaroid-style photos on the right side of their mirror. The user can grab a polaroid photo and the application will generate five possible avatars from which the user can select one and further modify if they wish.

\section{Method}

\subsection{Participants and Settings}

We are presenting a retrospective analysis of conversations, interactions, and design artifacts from a design group meeting. As designers, we wanted to collaboratively explore the possibilities that existing virtual reality tools might have for representing gender and sexual identities. The design team is comprised of all five authors and all were present in the design meeting. Our initial idea was to bring together a design team of friends with interests in virtual reality development. The design team decided prior to the meeting to record their interactions in case they came up with ideas for new technology designs. The design team members agreed to video recordings because it was easier than making written notes which would have prevented us from participating in the virtual reality activities. As the conversations ensued and became more personal, the first and second author checked that the design team members still wished to share their experiences. Half-way through the meeting, there was a food break during which the authors discussed and agreed that there was value in collaborating and sharing the design conversations at an upcoming STEM symposium. All participants agreed to serve as co-authors and share their personal stories and pictures of their artifacts. The order of authors was decided based on the contributions to conceptualizing and writing the paper. Member-checking was done by the first and second author several 
In: Sengupta et al. (Eds.) Critical, Transidisciplinary and Embodied Approaches in STEM Education (pp 307 - 328). Springer. Link: https://link.springer.com/chapter/10.1007/978-3-030-29489-2_17

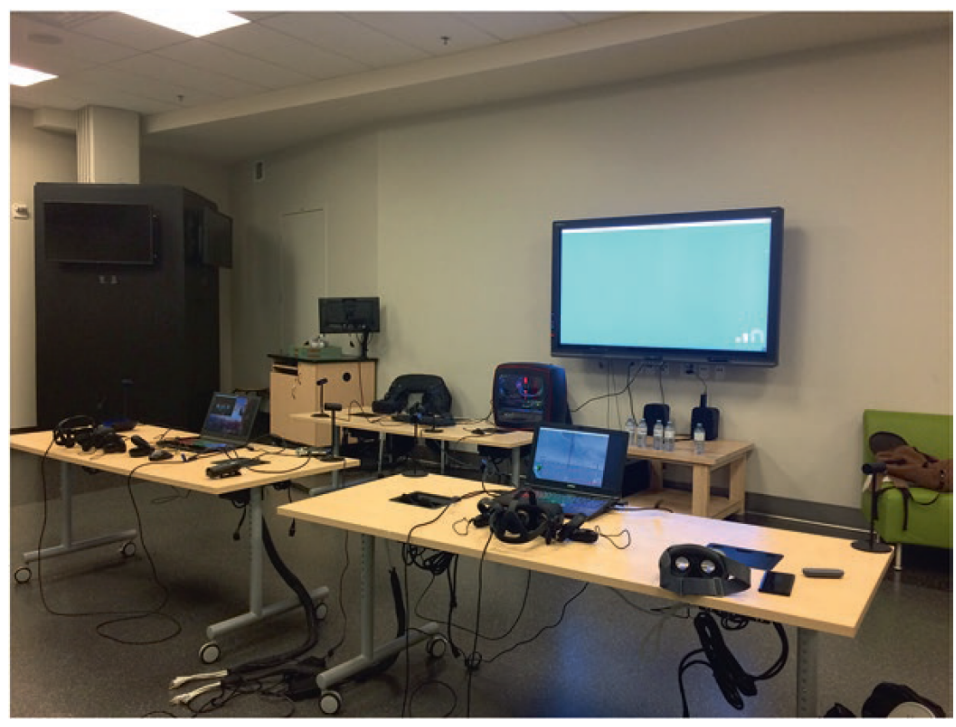

Figure 1: Room setup with three oculus rift virtual reality systems

times during the analysis and the writing of the paper in the form of informal meetings and phone and text conversations.

The analysis focuses on four of the design team members, who are all friends with each other, and in their early thirties. They all have gender nonconforming, queer identities and life histories. Some parts of their identities and life histories are shared and are presented in the analysis. The design team members who are the focus of this analysis are all white and were born and raised in Canada. The participants' pronouns are as follows: Scout (she/her), John (he/him), Matthew (he/him), and Dylan (they/them).

Scout is a professional 3D digital sculpture artist, who works in VR and non-VR applications. John is a computer programmer and works as an IT technician. Matthew is a game designer and worked as the manager of immersive technologies at the local science center. He has worked in the gaming industry in various roles for over a decade. Dylan is a $\mathrm{PhD}$ student in the Learning Sciences and has worked as an educator in gender and sexuality for post-secondary, community, and workplace settings. In addition, it is important to note that all participants had previous experiences with VR explorations. This enabled them to dive into the designed activities right away, instead of learning to use VR controllers and navigate VR worlds. This was important for the on-site time constraints that we were working within, although in future studies, our goal is to involve people who are new to VR.

We conducted the design meeting in the immersive technologies studio in a public museum in a Canadian metropolitan city, as part of a collaboration between the University researchers (authors of this paper) and the museum. The design meeting activities occurred over approximately 
In: Sengupta et al. (Eds.) Critical, Transidisciplinary and Embodied

Approaches in STEM Education (pp 307 - 328). Springer. Link:

https://link.springer.com/chapter/10.1007/978-3-030-29489-2_17

$4 \mathrm{~h}$. The first activity involved VR sculpting using the Oculus Medium VR sculpting application and Oculus Rift virtual reality systems (Fig. 17.1). The second activity used Facebook Spaces, a social VR space that includes forms of identity development and sharing, like avatar creation and "selfies," and involved undirected activity initiated by the one of the design team members that was not initially part of the design meeting planned activities. During the VR sculpting activity, the prompt provided to Scout and John asked them to think about their experiences of gender and sexuality, rather than normatively used identity labels such as "queer" or "trans." That is, we asked them to focus on experiences that they felt were meaningful for their own coming into their gender and sexual identities. Specifically, the prompt to design a symbolic object was phrased as, "Try to sculpt something that represents your experience of gender and/ or sexuality. For example, a time when your gender or sexuality was policed, challenged, or questioned." This shift away from a focus on normative gender and sexuality labels and towards complex, emergent expressions is grounded in queer theory.

The observed conversations and interactions between the participants were audio and video recorded. Recordings were transcribed and analyzed through a phenomenographic lens (Marton, 1981; Sengupta \& Shanahan, 2017). Central to phenomenography is attending to people's experiences of a phenomenon and how these experiences shape their behaviors, conceptualizations, and interpretations related to the phenomenon. This is particularly important for our theoretical focus on figured worlds and boundary work, which involves not only how we act in the world, but also how we conceptualize and interpret our actions and the environment where we are situated. To this end, a phenomenographic approach attends to relationships between the participants and the world around them, including conceptual thought, immediate experience, and physical behavior. In addition, phenomenography is also based on the premise that there is a deeper structural dimension that shapes experience that underlies the diversity and variability of participants' experiences and sense-making (Marton, 1986, pp. 41-42). This is important for our work, given that our experiences of gender and sexuality are "oriented" (Ahmed, 2006) by the social and historical forces at and across multiple levels: personal, interactional, and institutional (Risman, 2004). Therefore, our analysis focuses how the participants interactions, explanations, and responses reveal their ways of sense-making, and also some of the underlying structural forces that shaped their experiences, both historically and in-the-moment.

To this end, in our analysis, we focused on the relationship between participants' creative work in VR, their conversations with friends, and their gender and sexual life-histories and identities. A key characteristic of boundary objects is that they can be used by different people or groups in different ways - i.e., the same boundary object can take on different meanings in different social realms (Star, 1988; Shanahan, 2011). As Shanahan (2011) aptly put it, boundary objects have "interpretive flexibility," which is the form of data that we focus on in our analysis. Interpretive flexibility is deeply connected to the work of figuring, through which the participants constructed and represented their figured worlds. So, our analysis focuses on presenting relevant segments of the transcript and relevant images of 
In: Sengupta et al. (Eds.) Critical, Transidisciplinary and Embodied Approaches in STEM Education (pp 307 - 328). Springer. Link:

the participants' work that make explicit both how they engaged in the work of figuring - the active construction of meaning - and their interpretive explanations of the meanings of their VR sculptures. Our analysis thus shows that the figured worlds of the participants are also emergent and dynamically constructed through their interactions with creative work in VR and with each other. We also identify how elements of the computational infrastructure served as pivots, enabling participants to shift across multiple social realms of their experiences. That is, the theoretical lenses of figured worlds and pivots offer us language to describe the form of participants' sense-making, while the "content" of their sense-making - a key commitment of phenomenographic approaches - is evident in the rich descriptions of the illustrative cases we present in the findings.

\section{$5 \quad$ Findings}

Our analysis, presented in the form of illustrative cases, shows how participants' figured worlds of gender and sexuality emerge through the creation and use of pivots (Finding 1), how engaging playfully with friends in VR enabled them to represent their appearance in VR and find affirmation of their identity (Finding 2), and how playful conversations and 3D sculpting together with friends enabled some of the participants to talk about their experiences of hurt pertaining to their gender and queerness (Finding 3).

\subsection{Finding 1: Pivots and Figured Worlds of Gen- der and Sexuality}

When prompted to create an object in VR that represented a personally meaningful aspect of her gender and/or sexual identities, Scout, a professional VR artist and sculptor, initially sculpted a three-dimensional "gender key." She explained her work as follows:

So when I was sculpting, it was really interesting because you asked us to sculpt something that had to do with a time that our gender, specifically, a time that our, like, people felt that we were too much one way or another, and so, I was trying to think, like, 'Okay, what can I sculpt?' And so I started sculpting a key without thinking because it was the first thing that came to mind. And I was like, 'Oh, it's like the key of. . . the gender key!' But then as I was sculpting, another thing came to mind, and I was like, oh, I remember when I was younger, I didn't get my ears pierced until I was seventeen and I only got one ear pierced. And that's, like, really unusual for women, um, to only have one ear pierced.

In this excerpt, Scout explains that, for her, sculpting and imagining are deeply intertwined, in a manner that is analogous to Pickering's (2010) description of scientific practice as a "mangle" - an inescapable intertwinement of conceptual and representational work. Rather than first imagining what the sculpted object should be, Scout started with a key because that is what came to her mind. The key, or what became the 
In: Sengupta et al. (Eds.) Critical, Transidisciplinary and Embodied Approaches in STEM Education (pp 307 - 328). Springer. Link: https://link.springer.com/chapter/10.1007/978-3-030-29489-2_17

"gender key," is a pivot between figured worlds of heteronormativity and queerness. Pivots serve to shift us between different figured worlds, moving us from one representation and figured world to another. The pierced ear is a representation of the figured world of queerness, whereas the gender key serves as a meta-representation by serving as the pivot between two figured worlds - a figured world of heteronormativity and a figured world of queerness. For Scout, the gender key represented the struggle of being between conflicting figured worlds. In order to reflect upon and represent her experiences of gender and sexuality, Scout first began with representing this struggle of being between conflicting figured worlds. The meta-representation of the "gender key" signified the "in-betweenness" of two figured worlds. As a pivot, the "gender key" symbolically unlocked the movement from heteronormativity to queerness that arose in Scout's process of sculpting her life experience. The action of rendering shape to the initial sketch of the key reminded Scout of how she shaped her own body by piercing her one ear in order to represent her queer identity when she was a teenager. Sculpting the key became a pivot for Scout into a figured world of queerness. The gender key served as a meta-representational pivot - a key that would unlock the worlds of queerness for her by allowing her to belong to that world through re-making her body, thus shifting her from a figured world of heteronormativity into a figured world of queerness. The pierced ear then became a pivot for Scout to launch into deeper reflections about her queer past. She further explained:

So yeah, I only got one ear pierced and that was really unusual and I remember thinking at the time, 'Uhh, I don't know which ear is the gay ear.' But I wasn't out yet. [...] And a lot of gay men used to use that, right? But I got one ear pierced. I believe it was my right ear and uhh, I left it like that for two years and so that was a little, that was something that was, like, not quite correct for my gender, to only have one ear pierced, and so that was a memory that came up while I was sculpting that wasn't something I was thinking about. I actually hadn't thought about it at all until.. [...] I was already, like, a little bit queer compared to some of the, you know, girls in my school. I'd already been told I was too masculine by some of the boys.

Sculpting the gender key led Scout to remember a moment in her past when she had been reflecting on queer identity markers and ways of signaling queerness through re-making the body - an example of body-becoming (Lane, 2009), which emerged in Scout's reflections as a central part of her figured world of gender and sexual identity. She mentioned that her memory occurs prior to her coming out - meaning prior to publicly claiming a label outside of cisheteronormative expectations of gender and sexual identities. This suggests that her figured world of gender and sexuality was shaped through her own sense of incongruity with social expectations, as expressed by her peers who thought she was too masculine. She expresses her emerging awareness of this incongruity with gender and sexual norms in terms of being "a little bit queer compared to some of the, you know, girls in my school" and being told she was "too masculine by some of the boys." 
In: Sengupta et al. (Eds.) Critical, Transidisciplinary and Embodied Approaches in STEM Education (pp 307 - 328). Springer. Link:

Her story highlights a significant experience of body-becoming-i.e., her experience of inscribing gender and sexuality upon her own body - and it also presents a complex and nuanced image of her figured worlds of gender and sexuality as a teenager. Her figured world was at once improvisational and rooted in her implicit desire to be recognized as queer, while at the same time being grounded in her own interpretation of the heterosexual matrix.

\subsection{Finding 2: Play, Intimacy, and Desire for Recog- nition in VR}

The second activity in the design meeting (the Facebook Spaces application) was initiated by Matthew, whose life history of play shaped his desire to direct his friends into playful activities. He explains his ongoing commitment to play in his work:

I often will try to encourage, like people [at work], to play more. And very often in a work environment, you feel this automatic pushback, like, "Yeah, we value play," but like, the play has to have a purpose or we have to like be doing it, you know, to try to get at some learning. It has to be for "team-building" or something like that. And I try to push back against that has hard as I can to say that play has value for play on its own. And I know that there are benefits to development and benefits to socialization, but I feel like we shouldn't have to defend play. It should just be allowed to be play. Like, yes, it has benefits, but even if it doesn't, it has intrinsic value, I think.

In the context of our design meeting as well, Matthew explained that he was not even necessarily trying to consciously make everyone play. Matthew's own figured world has been shaped by and is centered around play and his desire to encourage play among others. This influenced him to invite all of us to play both in the sense of inviting us to use his work space to meet and in the sense of inviting us to play in the Facebook Spaces application.

Play among friends in Facebook Spaces became influential to the exploration of gender and sexual representation by developing intimacy and encouraging exploration of bodily representation and modification. One way in which play and body modification occurred was through drawing modifications. Scout and Matthew had learned that it was possible to draw items using the VR pencil that could then be attached to a player's avatar when Scout had drawn a pair of glasses which Matthew had been able to attach to his avatar's face. Scout went on to draw another object which Matthew then picked up, duplicated, and put on his avatar's ears to turn the objects into earrings. When Dylan entered into the application, they also attached the earrings to their avatar. In the following exchange, Scout, John, and Matthew discuss the significance of these objects:

Scout: I just love that you're both wearing those ridiculous earrings. They actually look fun. It's kinda cool. Do you guys 
In: Sengupta et al. (Eds.) Critical, Transidisciplinary and Embodied

Approaches in STEM Education (pp 307 - 328). Springer. Link:

https://link.springer.com/chapter/10.1007/978-3-030-29489-2_17

want to draw new earrings for yourselves?

John: They want to wear "Scout."

Scout: They want to wear..? Oh yeah! Earrings by Scout.

Matthew: A Scout original.

Scout suggests to Matthew and Dylan that they could create their own objects to wear, but John and Matthew both affirm that the objects created by Scout hold more meaning, signifying the importance of friendship that is attributed to the objects created by Scout. Earrings had been an important part of gender and sexual representation for Scout as demonstrated in her initial sculpt in the first activity. Earrings became a significant object in Facebook Spaces as well. They signified intimacy and friendship as objects created by Scout and worn by Dylan and Matthew, and they signified gendered objects that were playfully worn in ways that challenged their gendered meaning.

Another way that body modification became important to exploring gender and sexuality was through avatar modification. Within Facebook Spaces, the player can modify their avatar as they face a virtual mirror of their avatar's body, including head, torso, arms, and hands. Their avatar projection in the mirror moves with the player's movement, increasing the sense of embodying the avatar. Facebook Spaces requires the player to login to their Facebook social media account and in the avatar modification menu, the application will load profile pictures from the player's Facebook account. The player can grab a profile picture and the application will offer suggestions for avatars based upon the picture the player chooses. When Dylan entered the avatar modification menu, they noted that the avatar choices were not divided into binary genders where the player first chooses a gender and then subsequent avatar modification options are limited by the initial choice of gender. Instead, the application did not ask for a gender and offered a variety of modification choices as detailed in the above section on virtual reality environments used. However, when Dylan picked up a profile picture to see the suggested avatars the application would generate based on the picture, the suggested avatars all had long blond hair. Dylan tried choosing other profile pictures, but continued to receive the same suggestions despite having neither long nor blond hair.

Dylan went on to modify their avatar without using the suggested avatars to approximate a likeness to their real self. They faced another limitation in hair color. For Dylan, who often colors their hair non-natural colors, the available hair colors were a significant factor in limiting their ability to recognize themselves in their avatar. As Dylan encountered the limitations of the application, they voiced their frustration to their friends. Upon exiting the avatar modification menu, Dylan joined Matthew and Scout around the virtual table. Scout suggested that she might be able to modify Dylan's avatar to look more like them by drawing purple into their hair. Scout stretched her virtual arm out towards Dylan's head and Dylan exclaimed surprise at how real it felt to have Scout move into their personal (virtual) space. Once Scout colored Dylan's hair with purple, Dylan used the virtual selfie stick to see how they looked and posed for a picture (Fig. 17.2). 
In: Sengupta et al. (Eds.) Critical, Transidisciplinary and Embodied Approaches in STEM Education (pp 307 - 328). Springer. Link: https://link.springer.com/chapter/10.1007/978-3-030-29489-2_17

Dylan shared this selfie to their Facebook social media from within the application. Upon having their hair modified by Scout, Dylan gained a sense of recognition with their avatar and thus shared this representation of themselves. Body modification in real life is a part of Dylan's life history of body-becoming that could not be achieved in Facebook Spaces' avatar creation tool. Dylan's desire for self-recognition and identity affirmation in VR could be achieved through intimacy and informal gender play with friends. Later, Matthew came back to the selfie of Dylan and remarked on how he felt about it:

This is my favourite picture of Dylan so I'm going to make it really big. [Puts picture on VR "wall". Matthew and Dylan laughing.]

Although the Facebook Spaces application imposed limitations upon Dylan that impeded their ability to recognize themselves - a process of virtual body-becoming - Matthew and Scout found ways to support Dylan in modifying and being recognized in their avatar. Dylan explained after the experience what they had been thinking when Scout colored their hair:

It made me remember when I was in high school with Matthew. We used to get to school early and go to the men's washroom to style each other's hair. It was such a heteronormative, strict school, and I could have gotten into trouble for going into the men's washroom. We got into trouble with teachers for even saying the word 'gay' at that time. I remember how Matthew and I would do things like style each other's hair in the men's washroom and it was kind of a way to challenge that.

The gesture of Scout standing close to Dylan in VR and reaching into Dylan's personal (virtual) space to color Dylan's hair was an intimate one, not merely because of the physical proximity, but on a more profound note, because it helped Dylan recognize themselves in their avatar. Recognition of oneself in virtual reality is also an affirmation of Dylan's queerness through their appearance in virtual space - a form of body-becoming, essential for being queer. Similar to Ahmed's (2006) reminder of the work that it takes to be lesbian (as mentioned earlier in our theoretical discussion of compulsory heterosexuality), this is an example of the work that it takes to see oneself as queer in a virtual environment. It took a significant amount of work and collaboration - alongside intimacy - in order for the Dylan to be able to recognize themselves in VR, and this example also illustrates how intimacy with close friends can help significantly in this process. The selfie of Dylan's avatar, once Dylan felt comfortable with their recognition of themselves in the virtual world, became another object attributed with the meaning of supporting recognition - of virtual bodybecoming, achieved through intimate, informal gender play. Matthew's expression of appreciation for the selfie and gesture of support by putting the picture up on the VR "wall" further reinforced this meaning.

Overall, these intimate gestures of friends with each other around appropriating virtual artifacts to express their queerness created a shared 
In: Sengupta et al. (Eds.) Critical, Transidisciplinary and Embodied Approaches in STEM Education (pp 307 - 328). Springer. Link: https://link.springer.com/chapter/10.1007/978-3-030-29489-2_17 15

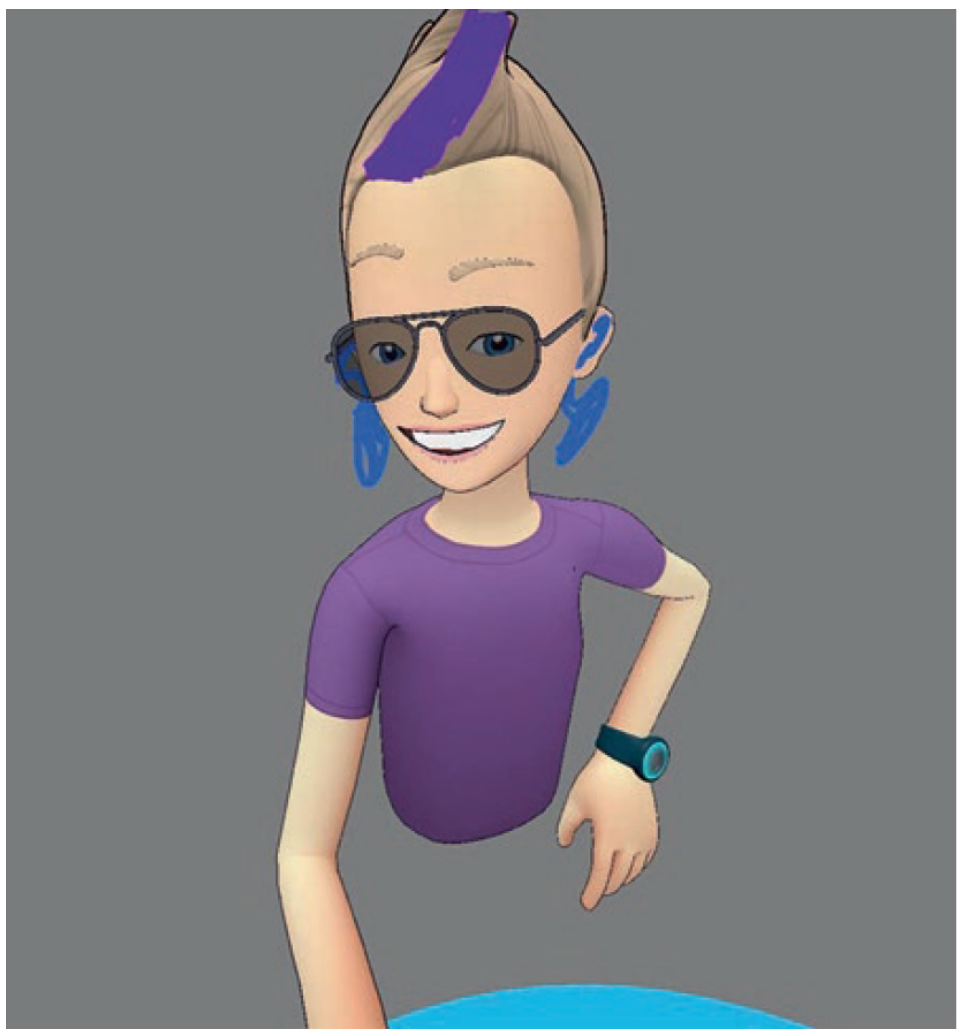

Figure 2: Dylan's avatar posing for a selfie within Facebook Spaces 
In: Sengupta et al. (Eds.) Critical, Transidisciplinary and Embodied Approaches in STEM Education (pp 307 - 328). Springer. Link:

figured world among the participants that was centered around supporting the desires of friends to recognize themselves and to be recognized by others in their genders and sexualities. This began with Matthew's desire to encourage play which created the context for intimacy and allowed for the support from friends that was necessary to modify avatars. At the same time, Scout's intimate gesture and interaction with Dylan's avatar acted as a pivot for Dylan into a past memory of being with Matthew and challenging the heteronormative and homophobic context of high school.

In these examples, we can see how play is an important context for expressing and affirming gender and sexual identities. As Ahmed (2006) demonstrates, a queer phenomenology orients us towards questions of who and what we are oriented towards as well as how we are oriented by others, which we can extend to our consideration of how the context of friendship and play orients us. In the context of our design meeting, figured worlds of queerness could be explored because of the factors of who, what, and how. The participants were oriented towards each other (who), because of their investment in their friendships, and towards each other's queer artifacts (what), because the artifacts (such as Scout's earrings in Oculus Medium and Facebook Spaces, or Dylan's avatar) became an object that a friend could interact with that could be played with in order to affirm (how) their meaning as queer objects. The participants were also oriented by the activities to explore their experiences of coming to understand their gender and sexuality and this orientation queered the context of learning and creating in virtual reality. The participants further engaged in this activity of queering virtual reality by affirming each other's queer identities and experiences.

\subsection{Finding 3: Sculpting "Hurt" Playfully: Jour- neys in Virtual Body-Becoming}

For Scout and John, gender and sexuality were shaped through their experiences of exclusion and incongruity in an existing cisheteronormative context among peers. As they proceeded further, their sculptures began to embody their experienced incongruities more viscerally and explicitly in the form of hurt. Interestingly, despite the gravity of the stories and emotions represented in their sculptures, play was an important element of this experience. In this section, we describe the final versions of the sculptures, and explain how the sense of playful exploration can create a context for virtual explorations in body-becoming, which in turn can facilitate deep explorations of issues pertaining to gender and sexual identities.

When John and Scout returned to the Oculus Medium application and finished their sculptures after playing in Facebook Spaces, their sculptures looked very different from what they had completed earlier. John continued with his sculpture of hangers and clothing, but now he used stamps from within the application of gendered male body parts (an arm and a torso) and hung the body parts from the hangers instead of using clothing as he had previously (Fig. 17.3).

John explains why his sculpture took this turn from clothing to body 
In: Sengupta et al. (Eds.) Critical, Transidisciplinary and Embodied Approaches in STEM Education (pp 307 - 328). Springer. Link: https://link.springer.com/chapter/10.1007/978-3-030-29489-2_17

parts as directly linked to the play experienced through the Facebook Spaces application:

In play it was all about being able to try something new and different, uh, colouring on each other, creating jewelry out of nothing, that, "hey, this is cool! do-do-do-do-do. Hey, look, I put it on my ear!" Little bits of creativity like that to almost exercise and get the mind going. Especially in that area of body exploration, which, as I say it, definitely, it brought forth ideas of my own body image and how it refers to gender, uh, and such. [...] Umm, in play it felt like I was being someone different, uh, being someone else, being playful, uh, being able to try different things as a different person. Here [in the second iteration of sculpting] was completely about how I perceived myself as I am, not really about what I want to be, or.. something I want to try. So I guess in that sense, being able to play and experience the different sides of myself gave me more perspective as to how I view myself and who I think I really am. If that makes sense?

John created a figured world where he could explore different sides of himself by creating and playing with gendered objects that sparked thinking and conversations about body exploration. This became the context for virtual exploration of John's body-becoming, as gendered objects (such as jewelry) became pivots for John into the figured worlds of the gendered body. When he returned to sculpting, John was able to reflect not only on how he challenged gendered, heteronormative ideas about clothing as a youth, but also his ongoing relationship with his body within the context of a cisheteronormative society. John reflected upon his K-12 experiences of enforced masculinity and cisheteronormativity; for example, he reflected upon when he wore a dress to play a female character in a school play. John explained that wearing a dress was treated as a joke by his peers, even though he experienced it as a form of playful gender expression, a form of body-becoming, that allowed him to explore aspects of his femininity.

Upon returning to sculpting, Scout's sculpture also took a stronger turn towards the body and gendered assumptions. Scout sculpted a mannequin torso and head with mixed gendered characteristics (Fig. 17.4).

On one side of the mannequin, she sculpted short hair and long eyelashes, and on the other side she sculpted the reverse and added a beard. On the torso she painted two checkboxes with the letter F, representing female, and the letter M, representing male. Stakes were driven through each box and into the torso. Scout explained that the sculpture represents how "if you express a mix of masculine and feminine characteristics, you are likely to experience double the injuries." Scout's addition to her sculpture further expresses her struggle of being between figured worlds of cisheteronormativity and queerness. She captures in her final sculpture the very painful and visceral limits one faces when trying to express one's gendered and sexual identity through the body when we cannot fully escape the cisheteronormative discourse of society which imposes 
In: Sengupta et al. (Eds.) Critical, Transidisciplinary and Embodied Approaches in STEM Education (pp 307 - 328). Springer. Link: https://link.springer.com/chapter/10.1007/978-3-030-29489-2_17 18

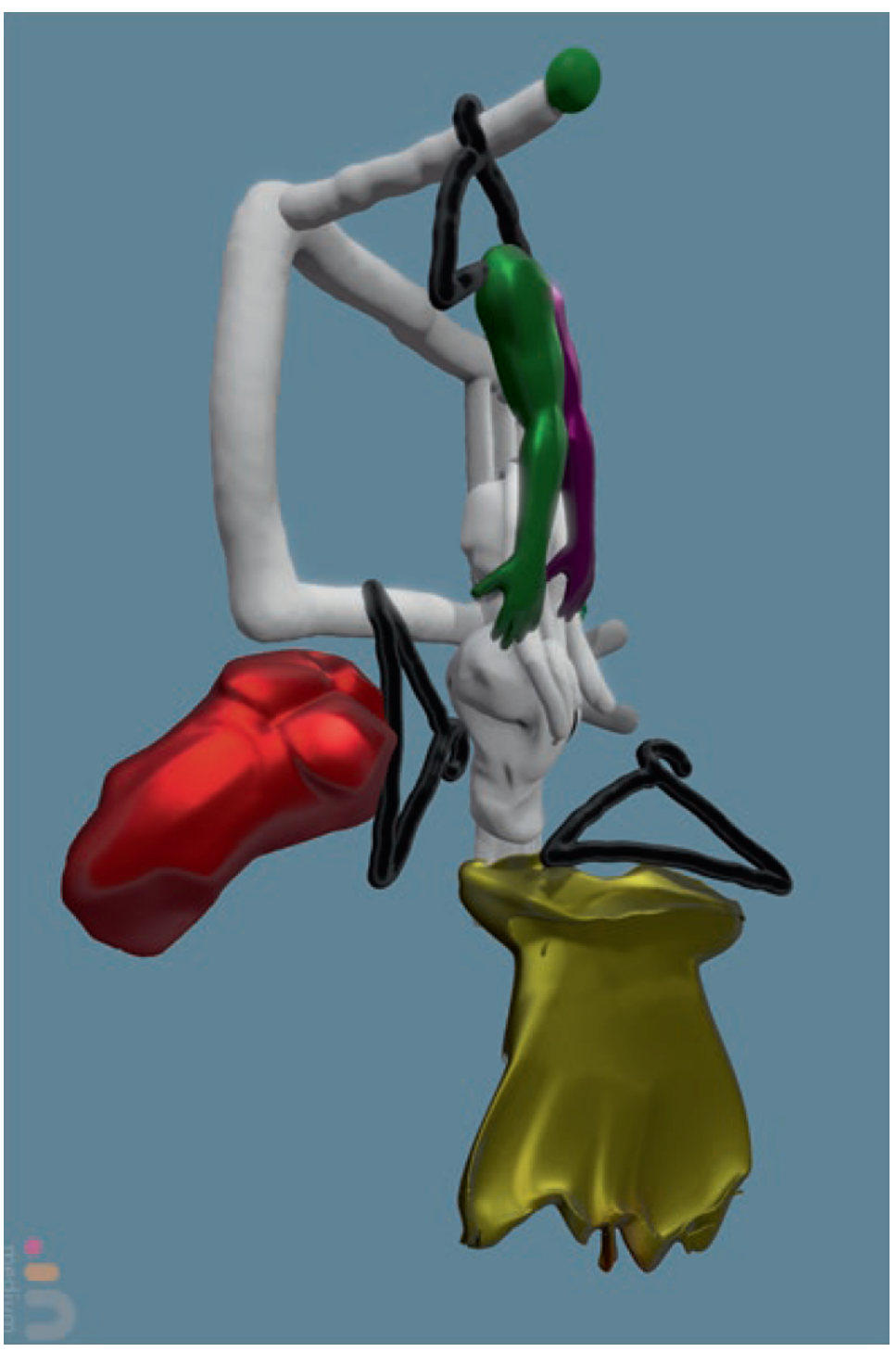

Figure 3: John's part of the sculpture showing a dress, two arms, and a torso (gendered male) hanging from hangers 
In: Sengupta et al. (Eds.) Critical, Transidisciplinary and Embodied

Approaches in STEM Education (pp 307 - 328). Springer. Link:

https://link.springer.com/chapter/10.1007/978-3-030-29489-2_17

the interpretive lens of "male" and "female," regardless of how we see and experience ourselves.

\section{Conclusions and Discussion}

\subsection{Analytic Summary: Intimacy, Pivots, and Vir- tual Becoming}

Overall, our analysis reveals how by creating boundary objects in the form of 3D sculptures and engaging in playful, creative work and discussions with friends, Scout and John were able to represent and voice how gender and sexuality come to be inscribed upon the body both through their own improvisational, playful acts of body-becoming and through the violence of cisheteronormativity imposed upon them. Play and intimacy were key elements of the participants' experiences. Gender-becoming is also body-becoming, and this was also true in VR. Scout's initial sculpture (a pierced ear) represented her own experience and desire to express her gender and sexuality through body modification, a playful act of bodybecoming through re-making her body. This improvisation in re-making her body demonstrates an exploration of her own figured world of gender as dynamic and playful, and in the process, she shared a story that she had never shared before with anyone besides her partner. Play and intimacy also created an environment that made the participants comfortable enough to share their hurt around their gender and sexual identities. For example, both of their final sculptures contained expressions of gendered violence inflicted upon bodies that do not conform to societal expectations of gender and sexuality.

In the cases we have presented, virtual objects serve as pivots in two senses. First, it is noteworthy that in the participants' improvisations, virtual body-becoming through $3 \mathrm{D}$ sculpting and avatar creation served as pivotal experiences for the participants in the sense that it enabled them to pivot between their lived histories and imagined selves. Once again, we see here the value of intimacy among friends, which created a context in which such experiences could be easily discussed without fear. Gender and sexuality becoming is not merely an individual act. As Butler (2006) and Lane (2009) poignantly argue, we experience gender and sexuality through our bodies as socially and culturally sanctioned ideologies of cisheteronormativity that we are expected to conform to with our bodies, and which is often imposed through gender violence. At the same time, virtual bodybecoming through avatar creation applications can pose limitations for self-recognition, particularly in this case for those who use body modification or who are otherwise nonconforming in their self-expression, as was evident in the case of Dylan, who was simply assigned a virtual avatar algorithmically by Facebook Spaces, which was inconsistent with their gender identity and expression. Play and intimacy between close friends, combined with tools for open modifications, like drawing and attaching virtual objects to one's avatar, can offer potential opportunities in such cases, especially for those with queer and trans identities. Here, virtuality serves as a pivot between an unwanted, algorithmically and socially as- 
In: Sengupta et al. (Eds.) Critical, Transidisciplinary and Embodied Approaches in STEM Education (pp 307 - 328). Springer. Link: https://link.springer.com/chapter/10.1007/978-3-030-29489-2_17 20

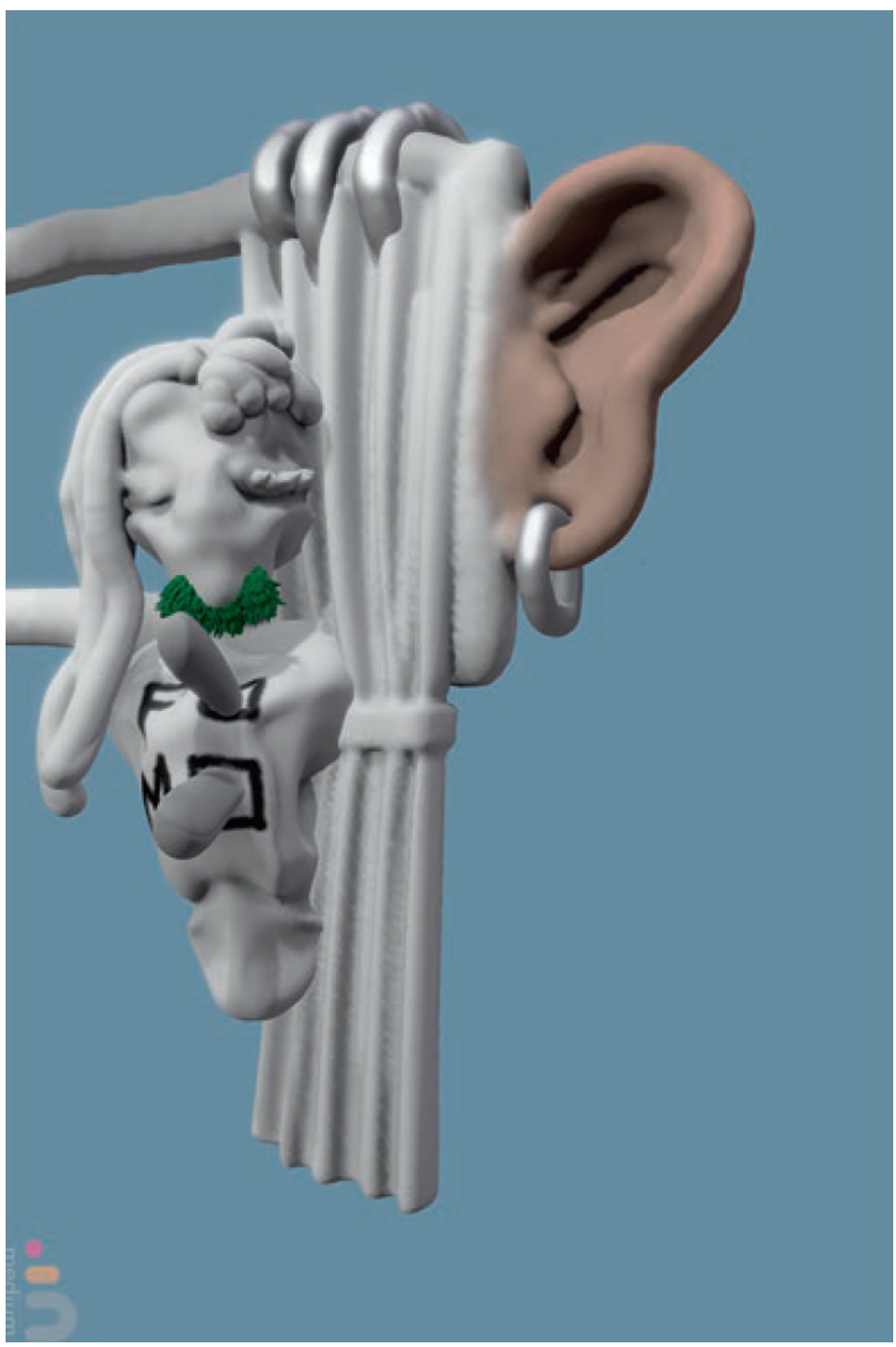

Figure 4: Scout's part of the sculpture showing a pierced ear on the side of a window frame with curtains and a mannequin torso 
In: Sengupta et al. (Eds.) Critical, Transidisciplinary and Embodied Approaches in STEM Education (pp 307 - 328). Springer. Link:

cribed gender expression and a more desirable one, as well as a shift away from gender expression being a solitary experience to being a place for being queer along with close friends. This turn towards a more social and more intimate experience of gender-becoming, along with friends, created opportunities for the participants to interweave their histories of being and becoming queer with playful, intimate interactions with their friends.

Sociologists have long reported that informal conversations and learning about sex, gender, and sexuality play an important role in shaping our gender and sexual identities (Risman \& Banerjee, 2013; Thorne, 1993). However, those studies also highlight how heteronormativity is reinforced through these informal conversations and interactions. Our work, in contrast, provides an illustrative example where innovations in STEM-for example, Virtual Reality and 3D Sculpting - can be queered to create a positive space for engaging in conversations and computational creative work about queer and trans identities by leveraging informality and intimacy between close friends.

\subsection{Queer Phenomenology, STEM, and the Learn- ing Sciences}

Our work challenges the learning sciences to take up questions of not only what we are oriented towards (i.e., what is worth learning), but also who we are oriented towards, and how we are oriented in our learning. On one hand, these questions are deeply phenomenological in nature (e.g., see Sengupta, Dickes, \& Farris, 2018), as they are invitations for us to peel off the sphere of givenness - the world as-is - i.e., as is given to us both in the form of canonical disciplinary knowledge in the classroom, and in the form of socially and culturally mandated ways of performing cisheteronormativity. The phenomenological agenda must then lead us to a place of originary sense-making (Merleau-Ponty, 1962), which, following Ahmed (2006), can directly challenge our entrenchment in cisheteronormativity. What is being learnt here, we believe, is not simply a matter of knowing in the disciplines; in contrast, the experiences reported here offer a fundamental shifting away from the "what" to the "who" as the topic of learning. That is, such queer and trans encounters with technology can move us away from reifying domains of knowledge, such as STEM, towards questions of who we were, who we are, and who we can become.

Such experiences can redefine our relationships with STEM innovations, such as VR and 3D sculpting, which can then become spaces and tools that serve the purpose of re-orienting us towards dynamic, emergent experiences of gender-becoming, while at the same time, de-orienting us away from our ubiquitous immersion in cisheteronormativity. Furthermore, in creating such spaces, we can also potentially reframe the purpose of learning sciences research as not merely phenomenological inquiry of learning, but also queering the phenomenology of learning (Ahmed, 2006). It enables us to imagine new ways of learning where we can engage in creative and incisive re-constructions of our individual histories and narratives, for example, in the contexts of gender and sexuality - that often carry a great deal of hurt and are usually silenced in public edu- 
In: Sengupta et al. (Eds.) Critical, Transidisciplinary and Embodied Approaches in STEM Education (pp 307 - 328). Springer. Link:

cation - through the collaborative creation of imagined futures with close friends.

\section{$7 \quad$ References}

- Abrahamson, D., \& Lindgren, R. (2014). Embodiment and embodied design. In R. K. Sawyer (Ed.), The Cambridge handbook of the learning sciences 2 (pp. 358-376), New York, NY: Cambridge University Press.

- Ahmed, S. (2006). Queer phenomenology: Orientations, objects, others. Durham, N.C.: Duke University Press.

- Ahn, S. J. G., Le, A. M. T., \& Bailenson, J. (2013). The effect of embodied experiences on self-other merging, attitude, and helping behaviour. Media Psychology, 16, 7-38.

- Azevedo, F. S. (2018). An inquiry into the structure of situational interests. Science Education, 102(1), 108-127.

- Bazzul, J., \& Sykes, H. (2011). The secret identity of a biology textbook: Straight and naturally sexed. Cultural Studies of Science Education, 6, 265-286.

- Berland, M., \& Lee, V. R. (2011). Collaborative strategic board games as a site for distributed computational thinking. International Journal of Game-Based Learning (IJGBL), 1(2), 65-81.

- Butler, J. (2006). Gender trouble: Feminism and the subversion of identity. New York, US: Routledge. (Original work published 1990)

- Cavanagh, S. (2010). Queering bathrooms: Gender, sexuality, and the hygienic imagination. Toronto, Canada: University of Toronto Press.

- Currah, P., \& Stryker, S. (2014). Postposttranssexual: Key Concepts for a Twenty-First-Century Transgender Studies. Spec. issue of TSQ: Transgender Studies Quarterly, 1-1.

- Davis, G. (2015). Contesting intersex: The dubious diagnosis. New York, U.S.: New York University Press.

- Davis, G., \& Murphy, E. L. (2013). Intersex bodies as states of exception: An empirical explanation for unnecessary surgical modification. Feminist Foundations, 25(2), 129-152.

- Esmonde, I., Brodie, K., Dookie, L., \& Takeuchi, M. (2009). Social identities and opportunities to learn: Student perspectives on group work in an urban mathematics classroom. Journal of Urban Mathematics Education, 2(2), 18-45.

- Farris, A. V., \& Sengupta, P. (2016). Democratizing children's computation: Learning computational science as aesthetic experience. Educational Theory, 66(1-2), 279-296.

- Glaser, B. G. (1965). The constant comparative method of qualitative analysis, Social Problems, 12, 436-445. 
In: Sengupta et al. (Eds.) Critical, Transidisciplinary and Embodied Approaches in STEM Education (pp 307 - 328). Springer. Link: https://link.springer.com/chapter/10.1007/978-3-030-29489-2_17

- Grace, A. P. (2015). Growing into resilience: Sexual and gender minority youth in Canada. Toronto, Canada: University of Toronto Press.

- Groom, V., Bailenson, J. N., \& Nass, C. (2009). The influence of racial embodiment on racial bias in immersive virtual environments. Social Influence, 4(3), 231-248.

- Holland, D., Lachicotte Jr., W., Skinner, D., \& Cain, C. (1998). Identity and agency in cultural worlds. Cambridge, U.S.: Harvard University Press.

- Hostetler, A., Sengupta, P., \& Hollett, T. (2018). Unsilencing critical conversations in social-studies teacher education using agent-based modeling. Cognition and Instruction, 36(2), 139-170.

- Jeppesen, S. (2016). Heteronormativity. In A. Goldberg (Ed.), The SAGE encyclopedia of lgbtq studies (pp. 493-496). Thousand Oaks," CA: SAGE Publications, Inc.

- Karkazis, K., Jordan-Young, R., Davis, G., \& Camporesi, S. (2012). "Out of bounds? A critique of the new policies on hyperandrogenism in elite female athletes." The American Journal of Bioethics, 12(7), 3-16.

- Kim, B., \& Ho, W. (2018). Emergent social practices of Singapore students: The role of laughter and humour in educational gameplay. International Journal of Child-Computer Interaction, 16, 85-99.

- Lane, R. (2009). Trans as bodily becoming: rethinking the biological as diversity, not dichotomy. Hypatia, 24(3), 136-157.

- Leander, K. M., \& Boldt, G. (2018). Design, Desire, and Difference. Theory Into Practice, 57(1), 29-37.

- Lindgren, R., \& Johnson-Glenberg, M. (2013). Emboldened by embodiment: Six precepts for research on embodied learning and mixed reality. Educational Researcher, 42(8), 445-452.

- Marton, F. (1986). Phenomenography - A research approach to investigating different understandings of reality. Journal of Thought, 21(3), 28-49.

- Marton, F. (1981). Phenomenography - Describing conceptions of the world around us. Instructional Science, 10(2), 177-200.

- Massumi, B. (2002). Parables for the virtual. Durham, N.C.: Duke University Press.

- Merleau-Ponty, M. (1962). The phenomenology of perception. London: Routledge and Kegan Paul. (Original work published in 1945)

- Mitchell, S. N., Reilly, R., Bramwell, F. G., Solnosky, A., \& Lilly, F. (2004). Friendship and choosing groupmates: Preferences for teacher-selected vs. student-selected groupings in high school science classes. Journal of Instructional Psychology, 31(1), 20-32.

- Oh, S. Y., Bailenson, J., Weisz, E., \& Zaki, J. (2016). Virtually old: embodied perspective taking and the reduction of ageism under threat. Computers in Human Behavior, 60, 398-410. 
In: Sengupta et al. (Eds.) Critical, Transidisciplinary and Embodied Approaches in STEM Education (pp 307 - 328). Springer. Link: https://link.springer.com/chapter/10.1007/978-3-030-29489-2_17

- Peck, T. C., Seinfeld, S., Aglioti, A. M., \& Slater, M. (2013). Putting yourself in the skin of a black avatar reduces implicit racial bias. Consciousness and Cognition, 22(3), 779-787.

- Pickering, A. (2010). The mangle of practice: Time, agency, and science. University of Chicago Press.

- Rich, A. (1980). Compulsory heterosexuality and lesbian existence. Signs: Journal of women in culture and society, 5(4), 631-660.

- Risman, B. J. (2004). Gender as a social structure: Theory wrestling with activism. Gender \& society, 18(4), 429-450.

- Risman, B. J. and Banerjee, P. (2013). Kids talking about race: Tween-agers in a post-civil rights era. Sociological Forum, 28(2), 213-235.

- Sengupta P., Dickes A., Farris A. (2018). Toward a phenomenology of computational thinking in STEM education. In M. Khine (Ed.) Computational Thinking in the STEM Disciplines (pp. 4972). Springer.

- Sengupta, P., \& Shanahan, M-C. (2017). Boundary play and pivots in public computation: New directions in STEM education. International Journal of Engineering Education, 33(3), 1124-1134.

- Shanahan, M-C. (2011). Science blogs as boundary layers: Creating and understanding new writer and reader interactions through science blogging. Journalism, 12(7), 903-919.

- Star, S. L. (1988). The structure of ill-structured solutions: Boundary objects and heterogeneous distributed problem solving. In A. H. Bond and L. Gasser (Eds.) Readings in Distributed Artificial Intelligence. San Mateo, CA: Morgan Kaufman.

- Stryker, S. (2013). (De) subjugated knowledges: An introduction to transgender studies. In S. Stryker \& S. Whittle (Eds.)., The transgender studies reader (Vol. 1), (pp. 1-17). New York, US: Taylor \& Francis.

- Takeuchi, M. A. (2016). Friendships and group work in linguistically diverse mathematics classrooms: Opportunities to learn for English language learners. Journal of the Learning Sciences, 25(3), 411-437.

- Travers, A. (2017). Transgender issues in sport and leisure. In L. Mansfield, J. Caudwell, B. Wheaton, \& B. Watson (Eds.) The palgrave handbook of feminism and sport, leisure and physical education, (pp. 649-665). London, UK: Palgrave Macmillan.

- Thorne, B. (1993). Gender play: Girls and boys in school. New Brunswick, N.J.: Rutgers University Press.

- Vea, T. (2019). The ethical sensations of im-mediacy: Embodiment and multiple literacies in animal rights activists' learning with media technologies. British Journal of Educational Technology. Advance online publication.

- Vygotsky, L. S. (1980). Mind in society: The development of higher psychological processes. Cambridge, MA: Harvard University Press. 
In: Sengupta et al. (Eds.) Critical, Transidisciplinary and Embodied Approaches in STEM Education (pp 307 - 328). Springer. Link: https://link.springer.com/chapter/10.1007/978-3-030-29489-2_17

- Westbrook, L., \& Schilt, K. (2014). Doing gender, determining gender: Transgender people, gender panics, and the maintenance of the sex/gender/sexuality system. Gender \& Society, 28(1), 32-57.

- Wittig, M. (1980). The straight mind. Gender Issues, 1(1), 103-111. 